\title{
To Belong or Not to Belong, That Is the Question: Terror Management and Identification With Gender and Ethnicity
}

\author{
Jamie Arndt \\ University of Missouri-Columbia
}

Jeff Schimel
University of Alberta

\author{
Jeff Greenberg \\ University of Arizona
}

Tom Pyszczynski

University of Colorado at Colorado Springs

\author{
Sheldon Solomon \\ Skidmore College
}

\begin{abstract}
The terror management prediction that reminders of death motivate in-group identification assumes people view their identifications positively. However, when the in-group is framed negatively, mortality salience should lead to disidentification. Study 1 found that mortality salience increased women's perceived similarity to other women except under gender-based stereotype threat. In Study 2, mortality salience and a negative ethnic prime led Hispanic as well as Anglo participants to derogate paintings attributed to Hispanic (but not Anglo-American) artists. Study 3 added a neutral prime condition and used a more direct measure of psychological distancing. Mortality salience and the negative prime led Hispanic participants to view themselves as especially different from a fellow Hispanic. Implications for understanding in-group derogation and disidentification are briefly discussed.
\end{abstract}

Terror management theory (TMT; Greenberg, Pyszczynski, \& Solomon, 1986; Solomon, Greenberg, \& Pyszczynski, 1991) posits that to function securely in the face of the uniquely human awareness of the inevitability of death, people live their lives embedded in a culturally derived conception of reality that provides meaning to experience and value to themselves. Group identifications are of course an important component of one's cultural context, and as many theorists have noted (e.g., Brewer, 1991; Lifton, 1983; Tajfel $\&$ Turner, 1986), group identifications play a major role in people's sense of who they are and how they feel about themselves. Thus, group identifications would be expected to play a significant role in how one manages concerns about mortality. Indeed, over a decade of research inspired by TMT has shown that after being reminded of their mortality, people are especially likely to defend cherished beliefs of groups with which they identify (for a review,

Jamie Arndt, Department of Psychological Sciences, University of Missouri-Columbia; Jeff Greenberg, Department of Psychology, University of Arizona; Jeff Schimel, Department of Psychology, University of Alberta, Edmonton, Alberta, Canada; Tom Pyszczynski, Department of Psychology, University of Colorado at Colorado Springs; Sheldon Solomon, Department of Psychology, Skidmore College.

This research was supported in part by National Science Foundation Grants SBR-9601366, SBR-9601474, SBR-9731626, and SBR-9729946. We thank Jessica Brown, Tiffany Brown, and Lindsey Henley for their assistance with data collection and Alison Cook for her assistance with different phases of the project.

Correspondence concerning this article should be addressed to Jamie Arndt, Department of Psychological Sciences, 111 McAlester Hall, University of Missouri, Columbia, Missouri 65211. E-mail: arndtj@missouri.edu see Greenberg, Solomon, \& Pyszczynski, 1997). According to the theory, such defenses protect against the potential for existential terror that the salience of death-related thoughts engender by more securely weaving the individual into a meaningful cultural fabric that, in turn, facilitates the maintenance of self-esteem. This analysis assumes, however, that one's identifications are positively regarded by the person and, consequently, are able to function as an effective buffer. Unfortunately, this is not always the case.

From the perspective of TMT, the anxiety-buffering function of group identifications derives from the capacity of such identifications to provide a sense that one is a valuable contributor to a meaningful reality. To the extent that the groups with which one is affiliated are positively valued, these identifications reflect positively on the self and thus provide a useful buffer against existential fears. However, if one's group is negatively valued, identification will reflect negatively on the self and thus interfere with one's efforts to maximize self-esteem and find existential security. This implies that reminders of mortality would reduce one's tendency to identify with groups when negative aspects of those groups are salient. The research reported in this article provides three converging tests of this hypothesis across two different types of group identities (gender and ethnicity) and three different dependent measures.

\section{Terror Management Theory and Research}

Derived in large part from the work of Ernest Becker (e.g., 1973), TMT posits that advanced cognitive abilities to think abstractly and symbolically led to the uniquely human awareness of the fragility of existence and the inevitability of one's own mor- 
tality. This awareness, when juxtaposed with a biological proclivity for self-preservation, creates the potential for existential terror. To manage this terror, people invest in, and identify with, cultural beliefs and ideologies. Investment in an individualized cultural worldview is posited to manage these anxieties by explaining one's existence - and the inevitable termination of it - within the context of a meaningful cultural reality that provides the possibility of literal or symbolic immortality to those who meet prescribed standards of value. The worldview is individualized in the sense that, although ultimately derived from the culture and thus sharing many commonalities within particular groups of people, it is tailored to the individual as a result of personal experience. Of importance, though, such faith in a worldview in and of itself is not enough. The theory posits that people must also feel that they are meeting the standards of value that are part of their cultural reality to qualify for the protection it affords. Thus, faith in a meaningproviding worldview and self-esteem based on the prescriptions of value of that worldview are dual components of an anxiety buffer that allows people to function with equanimity despite their awareness of their own vulnerability and ultimate mortality.

Over 100 separate studies conducted in seven countries have provided support for this theory. With regard to the anxietybuffering function of self-esteem, studies have shown that when self-esteem is experimentally increased or dispositionally high, participants exposed to threatening stimuli exhibit less selfreported anxiety, physiological arousal, and anxiety-related defensiveness (Greenberg et al., 1993; Greenberg et al., 1992). Converging support comes from studies showing that reminding people of their mortality (mortality salience) leads to increased self-esteem striving. Specifically, studies have shown that mortality salience (a) increases identification with aspects of self that provide self-esteem and disidentification with aspects of self that threaten self-esteem (e.g., Goldenberg, McCoy, Pyszczynski, Greenberg, \& Solomon, 2000); (b) increases the tendency to behave in accordance with one's values (e.g., Taubman Ben-Ari, Florian, \& Mikulincer, 1999); (c) increases one's distress when behaving in a way that violates cultural norms (Greenberg, Simon, Porteus, Pyszczynski, \& Solomon, 1995); and (d) increases optimal distinctiveness striving (Simon et al., 1997). Additionally, both dispositionally high and experimentally increased levels of self-esteem reduce the accessibility of death-related thoughts after a mortality salience prime (Harmon-Jones et al., 1997), and providing convincing evidence of the existence of some form of life after death eliminates the increased self-esteem striving otherwise found in response to mortality salience (Dechesne et al., 2001).

Studies examining cultural affiliations and faith in one's cultural worldview have shown that mortality salience leads to (a) harsher judgments of those who violate cultural norms and more favorable judgments of those who uphold cultural principles (e.g., Florian \& Mikulincer, 1997); (b) increased attraction to those who explicitly praise aspects of the cultural worldview and decreased attraction to those who criticize it (e.g., Greenberg et al., 1990); (c) increased in-group favoritism, behavioral avoidance of out-group members, stereotyping, and prejudice (e.g., Ochsmann \& Mathay, 1996); (d) increased aggression against those who challenge one's beliefs (McGregor et al., 1998); and (e) increased perceptions of social consensus for one's attitudes, especially when one is in the minority (e.g., Pyszczynski et al., 1996). TMT researchers have used a variety of operationalizations of mortality salience (e.g., fear of death scales, films of fatal accidents, proximity to a funeral home, subliminal death primes) and have shown that thoughts of other aversive events, such as failing an exam, dental pain, giving a speech in front of a large audience, becoming paralyzed, or being socially excluded do not produce effects parallel to mortality salience (for a review, see Greenberg et al., 1997).

The overall tenor of the terror management literature is that mortality salience leads people to be more positively disposed toward people or ideas that support their worldview and selfesteem and more negatively disposed toward people or ideas that threaten these two psychological entities. Because the groups to which one belongs typically support one's anxiety-buffering beliefs and values, this normally entails increasing one's affiliation with these groups. However, these studies raise an interesting question: What happens when one's group identifications are likely to reflect negatively on one's self-esteem? Answering this question may provide further insight into some of the particular motivations that reminders of death provoke.

\section{Negative Aspects of Group Identification}

Social identify theory (Tajfel \& Turner, 1986) and various other social psychological perspectives (e.g., Allport, 1954; Tesser, 1988) posit that people are motivated to view their groups in a positive light so as to maximize the self-esteem implications of their group membership. However, there are clearly situations in which it is difficult to deny the negative features, past and present, real or imagined, of one's in-group. As one example of such situations, Doosje, Branscombe, Spears, and Manstead (1998) described culture guilt and provided evidence from both laboratory and field studies that when negative aspects of one's group are salient, people experience collective guilt, even in the absence of any personal responsibility for the transgressions. They suggested that the ambivalence of many young Germans about their national identity might be at least partially due to their knowledge of their country's role in the atrocities of the Holocaust. In a related vein, Branscombe (1998) demonstrated that when White Americans or men are reminded of unjustified privileges they have received because of their group membership, they experience decreased self-esteem. Indeed, most cultural groups have at least some skeletons in their closets, consisting of reprehensible behavior by their group or individual members of their group that limits their members' ability to maintain in-group pride.

The burden of negative information about one's group and its members may be an especially potent problem for members of minority and other stigmatized groups, both because of the negative stereotypes that exist and because of the tendency for others to believe that the negative behavior of one individual represents the underlying tendencies of the group as a whole (cf. Allport, 1954; Hamilton \& Gifford, 1976). Indeed, as another example of negative aspects of group identification, a vast literature documents the negative consequences, from interpersonal to occupational, of being perceived as a stereotypic member of a stigmatized group (see, e.g., Crocker \& Major, 1989, for a review). Moreover, research indicates that the impact of such stigmatization affects not only how others treat members of stigmatized groups but also the psychology of stigmatized individuals themselves. Studies on ste- 
reotype threat indicate that members of stigmatized groups are often worried that they might confirm a negative stereotype of their group and that this threat affects their performance in stereotype-relevant domains (e.g., C. M. Steele, 1997). Of note, this literature suggests that virtually all groups are vulnerable to these effects, even those typically construed as the majority. For example, Stone, Lynch, Sjomeling, and Darley (1999) capitalized on the stereotype "White men can't jump" and recently found that when White males are exposed to this stereotype, their performance suffers on a test of athletic prowess.

Although membership in stigmatized groups may at times have negative consequences, research has shown that the self-esteem of individual members of such groups is not reliably less positive than that of majority group members (e.g., Rosenberg, 1981; Wylie, 1979). To explain this apparent contradiction, Crocker and Major (1989) proposed that minority group members possess a variety of defense mechanisms to buffer the potential psychological consequences of minority group membership. For example, members of minority groups sometimes adjust their attributions for negative feedback to defuse the adverse psychological impact of such evaluations (Crocker, Voelkl, Testa, \& Major, 1991). As social identity theory (Tajfel \& Turner, 1986; see also Brewer, 1991) suggests, people actively pursue those social identities that optimize effective psychological functioning by providing selfesteem, a distinctive identity, and a way of understanding one's place in the social world. Thus, another strategy to protect selfesteem is to deny one's group membership or distance from the negatively perceived group. In addition to their implications for self-esteem, the constellation of beliefs surrounding social identities also helps the individual make sense of the social world that he or she inhabits. This is true for members of both privileged majorities and underprivileged minorities. Recent work on false consciousness and system justification by Jost and colleagues (e.g., Jost, 1995; Jost \& Burgess, 2000) has suggested that individuals will sometimes not rebel against negative beliefs and attitudes toward their group because maintenance of such views serves to justify the ideological structure or dominance hierarchy of the society. From a TMT perspective, this work suggests that people sometimes view their own group in a negative light because doing so helps fulfill the cultural worldview's way of providing order and meaning to reality. However, the threat to self-esteem that results from accepting such negative beliefs about one's group may also motivate such persons to disidentify from their in-groups, as long as the particular in-group is not the individual's sole basis of meaning and value. Using the parlance of Jost and Banaji (1994), individuals must pursue ego justification needs as well as group or system justification needs.

Indeed, from a terror management perspective, self-esteem is a central component of the security-providing cultural anxiety buffer, particularly necessary when death-related thoughts are close to consciousness, as the evidence that mortality salience increases self-esteem striving shows. Therefore, mortality salience should lead to greater care and selectivity in seeking and avoiding group affiliations that are likely to impinge on self-esteem. Consistent with this reasoning, two recent studies inspired by the classic research on basking in reflected glory (Cialdini et al., 1976; Snyder, Lassegard, \& Ford, 1986) have shown that mortality salience leads to increased identification with one's in-group un- less such group identification is likely to reflect negatively on the self (Dechesne, Greenberg, Arndt, \& Schimel, 2000). The first study found that after mortality salience, Dutch participants espoused greater optimism regarding the outcome of a soccer match between their national team and a German squad. The second study showed that American participants responded to mortality salience by identifying more strongly with their university football team just prior to the beginning of the fall football season; however, after that team lost their first game, mortality salience led to decreased affiliation with the team and increased identification with the university basketball team.

\section{Overview of the Present Research}

The studies reported in this article explored the implications of TMT and the emerging work on negative social identity for understanding enduring in-group affiliations, particularly in response to stereotype threat or other information that could undermine the value of identifying with one's in-group. In three studies, we conducted converging tests of the hypothesis that although under most circumstances mortality salience increases identification with one's in-group, it reduces such identifications when negative information or stereotypes about one's group are salient. We propose that such a response reflects the propensity for mortality salience to motivate the need to maintain self-esteem, even if at the expense of belongingness or in-group favoritism. Study 1 investigated women's perceptions of similarity to most members of their gender under conditions of low or high gender-based stereotype threat. Study 2 investigated the effect of mortality salience and a negative media depiction of an individual member of one's group on evaluations of the work of fellow in-group members. Study 3 more directly assessed the tendency to psychologically distance from individual members of one's in-group. Across all three studies, we hypothesized that mortality salience would encourage identification with one's in-group under normal conditions but would discourage identification with one's in-group when such identification was likely to reflect negatively on one's self-esteem.

\section{Study 1}

In Study 1, we adopted Spencer, Steele, and Quinn's (1999) procedure for inducing stereotype threat among women by having them anticipate taking a math test. C. M. Steele and Aronson (1995) suggested that because group stereotypes are widely known throughout a given society (e.g., Devine, 1989), individual members of stereotyped groups are painfully aware of these beliefs. When faced with a situation in which the stereotype might plausibly be applied, members of the stereotyped group fear that they might confirm that stereotype and, consequently, perform poorly on subsequent tasks. Research indicates that priming the Black stereotype can lead African American college students to deny their similarity to the Black stereotype (C. M. Steele \& Aronson, 1995) and that African American students disengage their selfesteem from performance situations that implicate negative group stereotypes (Major, Spencer, Schamder, Wolfe, \& Crocker, 1998). Relatedly, women have been found to distinguish themselves from their gender group when the low status of women as a minority is made salient (Swan \& Wyer, 1997). The present study examined 
the hypothesis that following mortality salience, the threat of a negative stereotype of one's own group would reduce in-group identification.

Female participants were first told that they would be completing standardized test problems and were then given sample questions from the math or verbal test they would purportedly be taking later in the experimental session. They also indicated their gender on the test booklet (cf. C. M. Steele \& Aronson, 1995). They were then given the mortality salience or control manipulation, after which they completed a social projection measure, based on Krueger and Clement (1994). With this measure, participants rate their attitudes as well as those of people in general, and then the convergence between the two is assessed (after controlling for social desirability). In the present study, we adjusted the reference group to refer specifically to women. Thus, the measure becomes a variant of that used to assess self-stereotyping, that is, the perception of oneself as a prototypical group member (e.g., Biernat, Vescio, \& Green, 1996; Spears, Doosje, \& Ellemers, 1997). We expected that in the absence of stereotype threat, mortality salience would lead women to increase perceptions of themselves as similar to women in general. However, because mortality salience increases the need for self-esteem, we expected this effect to be minimized or reversed under conditions of high stereotype threat.

\section{Method}

Participants and design. Forty-seven female introductory psychology students at the University of Missouri participated in return for course research credit. Participants were run in groups of 3 to 6 per session and were randomly assigned to conditions in a 2 (stereotype threat: math test vs. verbal test) $\times 2$ (salience: mortality vs. dental pain) between-subjects design. The dependent variable was a social projection measure that assessed alignment of one's attitudes with "women in general." A male and female experimenter ran roughly equal numbers of participants in each condition.

Procedure. On arriving at the laboratory, participants were told that the study concerned how personalities change over time and how these changes relate to changing academic abilities in different domains. Participants were told that they would complete some personality questionnaires and then be given $20 \mathrm{~min}$ to complete a timed section from the Scholastic Aptitude Test (SAT). Participants were assured that their responses were anonymous; to ensure their privacy they would complete all materials at partitioned work stations and place their materials in blank envelopes, to be deposited in a communal box. Participants then read and signed a consent form.

A first packet of materials contained two filler items followed by the mortality salience or dental pain salience questionnaire. The mortality salience treatment (Rosenblatt, Greenberg, Solomon, Pyszczynski, \& Lyon, 1989) consisted of having participants respond to two open-ended questions: "Please briefly describe the emotions that the thought of your own death arouses in you" and "Jot down, as specifically as you can, what you think will happen to you physically as you die and once you are physically dead." The dental pain salience control treatment consisted of parallel questions about the experience of dental pain. All materials were prepared in advance, thus keeping the experimenter blind to conditions.

After participants completed the personality questionnaires, the experimenter reminded them of the SAT portion of the study. Participants were given another blank envelope containing the materials for this test and were asked to read the instructions and then get started. The introductory information on the cover sheet constituted the manipulation of stereotype threat. Half of the participants (all of whom were female) read that they were to take a math section of the SAT, and the other half read that they were to take a verbal section of SAT. All participants were then asked to indicate their gender and age on the cover page. As Spencer et al. (1999) have shown, reminding women of their gender in the context of having to take a math test induces stereotype threat. However, no such threat should occur in the verbal test condition, because this is not an aspect of negative female stereotypes. To enhance the believability of the exercise, we also included in the envelope the (math or verbal) test questions the participants expected to answer.

Once all participants had looked over the materials, the experimenter remarked that she had forgotten to bring the Scantron bubble sheets for their answers. The experimenter remarked that she would retrieve them now but that participants should not start the questions because she had to be there to time them. The experimenter then suggested that while she was getting the answer sheets, participants could fill out another personality questionnaire. Participants were then given the social projection measure along with another blank envelope in which to put it when finished.

The social projection measure, which constituted the primary dependent variable, was, with one notable exception described below, the same measure used in Simon et al. (1997) and Arndt, Greenberg, Solomon, Pyszczynski, and Schimel (1999), which in turn was adapted from Krueger and Clement (1994). The 16 items in the measure were selected from the Minnesota Multiphasic Personality Inventory-2 (MMPI-2; Butcher, Dahlstrom, Graham, Tellegen, \& Kaemmer, 1989) and were neutral with respect to endorsement leading to self-esteem enhancement or threat (e.g., "I like poetry," "I enjoy reading love stories," "I would like to be a singer," "I like to read newspaper articles on crime," and "I like collecting flowers or growing house plants"). Participants rated these items with respect to three dimensions. The first time the items were presented, participants reported their endorsement of each item on a 9-point scale $(1=$ no agreement at all to $9=$ total agreement). The items were then presented again, and participants were asked to write down the percentage of women in general that they thought agreed with each statement, using any percentage from 0 (no one in the general female population agrees with the statement) to 100 (everyone in the general female population agrees with the statement). Changing the reference group for this question from "people in general" to "women in general" was the one adjustment that was made to the materials for the purpose of this study. The last time participants saw the items, they were to indicate how socially desirable they thought it was to agree with each statement, using a 9-point scale $(1=n o t$ at all socially desirable to $9=$ totally socially desirable $)$. After participants finished this measure, they were probed for suspicion and debriefed.

\section{Results}

To assess our predictions concerning social projection to other women, we followed Krueger and Clement's (1994) procedure of computing the partial correlation between endorsements and consensus estimates, controlling for social desirability ratings (see also Arndt et al., 1999; Simon et al., 1997). Higher scores reflect more social projection, and thus identification, with other women. We used both a male and female experimenter because it is plausible that the gender of the experimenter could affect women's social projection to other women after mortality salience and stereotype threat. Thus, to examine our primary hypothesis about the effects of mortality salience and stereotype threat, as well as this possibility, we conducted a 2 (mortality salience) $\times 2$ (stereotype threat) $\times 2$ (gender of experimenter) analysis of variance (ANOVA) on the social projection scores. This analysis revealed only the predicted Mortality Salience $\times$ Stereotype Threat interaction, $F(1,46)=5.80, p<.03$, which was not qualified by the 
gender of the experimenter $(F<1) .{ }^{1}$ Cell means are presented in Table 1.

We then conducted pairwise comparisons to assess our specific predictions. After being reminded of their mortality and confronting a verbal section of the SAT (low stereotype threat), participants identified more strongly with their group by showing higher social projection than their dental pain counterparts, $t(46)=3.01, p<$ .05 . However, this difference between mortality and dental pain salient conditions was completely eliminated when participants confronted a math section of the SAT (high stereotype threat; $t<$ 1). Looked at differently, social projection levels did not differ between math and verbal SAT participants in the dental pain conditions $(t=1.23)$. However, after mortality salience, participants engaged in less social projection in the high stereotype threat condition than in the low stereotype threat condition, $t(46)=2.09$, $p<.05$.

\section{Discussion}

These data demonstrate that stereotype threat eliminates women's tendencies to increase their identification with their gender in response to mortality salience. When female participants were told that they would take a verbal SAT, a prospect not likely to activate negative stereotypes about women, mortality salience led them to increase identification with their gender by perceiving themselves as more similar to women in general. This finding conceptually replicates previous findings that mortality salience increases group identification and defense but extends these findings to gender identification. However, when female participants expected to take a math test, a prospect likely to activate negative stereotypes of women, they no longer responded to mortality salience with increased gender identification. The present study thus demonstrates that although mortality salience typically increases group identification, this does not occur when negative implications of group membership are salient.

As noted in the Results section, in the dental pain control conditions of the present study, there was no significant difference between stereotype threat and non-stereotype threat participants in their social projection to other women. At first glance it might therefore appear that we did not replicate previous work documenting that in the absence of mortality salience, stereotype threat

\section{Table 1}

Cell Means for the Salience $\times$ Stereotype Threat Interaction on Social Projection in Study 1

\begin{tabular}{lcc}
\hline SAT test & Mortality salient & Dental pain salient \\
\hline Verbal & & .08 \\
$M$ & .42 & .26 \\
$S D$ & .32 & 11 \\
$n$ & 11 & .22 \\
Math & .19 & .31 \\
$M$ & .24 & 13 \\
$S D$ & 12 & \\
$n$ & & \\
\hline
\end{tabular}

Note. Means reflect the partial correlation between participants' own endorsements and consensus estimates for women, controlling for social desirability. High numbers reflect more social projection. leads individuals to dissociate themselves from their group (e.g., Swan \& Wyer, 1997). However, we used a much more subtle stereotype threat induction than that used by Swan and Wyer (1997). Their study manipulated whether participants were in the numerical minority or majority and also had them rate themselves along gender-stereotypical traits and make judgments for a genderambiguous target person. Moreover, in contrast to most stereotype threat studies, our participants did not actually take the threatening test, an experience that would be expected to intensify concerns with confirming the stereotype and increase the ego threat inherent in the situation. The fact that reduced gender identification in response to stereotype threat did occur in the mortality salient condition is consistent with the idea that self-esteem needs are especially high when mortality is salient, a proposition that has been supported by a fairly large body of previous research (for a review, see Pyszczynski, Greenberg, \& Goldenberg, in press). Finding an effect of stereotype threat when self-esteem needs are elevated also provides further evidence of the role of self-esteem needs in stereotype threat effects, an assumption central to theorizing on these processes (cf. Steele \& Aronson, 1995).

Questions could be raised, however, as to whether our index of social projection reflects perceived similarity specifically to women or, rather, to people in general. Although the measure assessed correlations between self-ratings and ratings of women, the absence of an assessment of similarity to people in general makes it possible that our participants were not differentiating between women as a group and people in general and that our measure therefore reflects a form of perceived similarity to people regardless of gender. This seems an unlikely alternative explanation, because we can think of no theoretical foundation for the obtained findings on the basis of this reasoning: Why would a stereotype threat specific to the female gender lead participants to be reluctant to see themselves as similar to other people in general? In the absence of a plausible alternative, the present analysis stands as the most reasonable explanation of these results. Nonetheless, additional studies were conducted to provide converging evidence that mortality salience can engender a need to disidentify from groups that threaten self-esteem.

\section{Study 2}

In Study 1, although stereotype threat eliminated the tendency for mortality salience to lead women to perceive themselves as more similar to women in general, it did not combine with mortality salience to lead them to perceive themselves as less prototypical of their gender than non-mortality salient women. Thus,

\footnotetext{
${ }^{1}$ There was a marginally significant Experimenter $\times$ Salience interaction, $F(1,46)=4.10, p<.06$, on the social projection scores. Briefly, this interaction reflected increased projection among mortality salient women run by the male experimenter relative to their dental pain counterparts but no such increase for women run by the female experimenter. Given that there were only women in the study, the presence of the male experimenter in conjunction with mortality salience may have made female identity a more viable way to restore self-esteem. However, because this interaction did not involve the stereotype threat manipulation and did not compromise the critical Salience $\times$ Stereotype threat interaction, it is not central to our present concerns and is not discussed further.
} 
there was no direct evidence of a mortality-salience-induced active disidentification response. It may be that a more negative framing of one's group is required for such active disidentification to occur. In American culture, such negative framing may be especially likely to be experienced by members of ethnic minority groups.

Although research has shown that the psychological impact of evaluations of one's group is not restricted to members of minority groups (e.g., Branscomb, 1998; Cialdini et al., 1976; Dechesne, Janssen et al., 2000), we reasoned that the negative self-esteem implications of group membership might be especially apparent among members of minority groups for several reasons. First, as McGuire and Padawar-Singer (1976) have shown, features of the self that are relatively unique or rare tend to become especially salient features of one's self-concept. Because membership in a minority group usually (though not always) entails being in the numerical minority in most situations, one's minority group status is likely to be an especially salient aspect of one's identity. In addition, both the prejudice and discrimination that many minority groups face in contemporary society and the well-intentioned efforts of many majority group members to actively avoid such prejudicial treatment are likely to further increase the salience of group identity for minority group members. Because of this greater salience of group identity for members of minority groups, such individuals may be particularly susceptible to situational influences on how they think about their group identity (e.g., Allport, 1954; Crocker \& Major 1989; Deaux, 1993; Doosje et al., 1998; Jost, 1995; C. M. Steele, 1997). On the one hand, their heritage may be a powerful source of meaning and value; on the other hand, the discrimination and prejudice displayed by the majority may also lead to negative associations with one's group identity that undermine self-esteem as defined by the prevailing cultural worldview. When this negative aspect of one's minority identity is salient, mortality salience may thus lead to reduced affiliation with one's ethnic heritage.

Of course, individuals whose membership in an ascribed group is based on such factors as ethnicity are likely to face great difficulties abandoning their group identification. Research has indicated, however, that at least for Hispanic students, the early years of university life may be a time when such identification is renegotiated in the face of contextual change (Eithier \& Deaux, 1994). Indeed, when confronted with threats to their ethnic identity, first-year Hispanic students who were more ambivalent about their ethnicity showed decreases in self-esteem and lowered ethnic identification. In this research, a change in context had the capacity to significantly alter the meaning of, and value derived from, a particular group identity (Deaux, 1993).

One indicator of such disidentification might be a propensity to negatively evaluate members of one's own ethnic group. The idea of minimizing the sting of belonging to a group that is devalued by derogating other members of the group is an old one that has been discussed by Lewin (1941), Bettelheim (1943), Child (1943), and Allport (1954), among others. Allport discussed it in the context of intropunitive ego defenses resulting from being a target of prejudice and suggested that it may help the individual identify with the majority group and deflect blame for the negative image of one's group onto in-group members other than oneself. Empirically, the Clark and Clark (1947) research (which was instrumental in starting the desegregation movement), in which Black children showed a preference for White over Black dolls, could be viewed as evidence of this phenomenon. However, despite extensive discussion of this issue over the years, more research is needed to investigate this phenomenon in adults and the conditions under which it is most likely to occur. We hypothesized that the negative framing of the ethnic group in combination with mortality salience may be one set of such conditions.

Support for this hypothesis would also inform our understanding of the nature of mortality salience effects. Whereas a large body of research has shown that people often respond to mortality salience by derogating members of stigmatized out-groups (e.g., Florian \& Mikulincer, 1998; Greenberg et al., 1990; Nelson, Moore, Olivetti, \& Scott, 1997), to date the terror management literature has shown only positive evaluations of one's in-group in response to reminders of one's mortality. Although Dechesne, Greenberg, et al. (2000) have demonstrated that mortality salience can lead to reduced affiliation with one's college football team after a loss, we know of no previous evidence of mortality salience leading to derogation of other in-group members. Whereas previous research has shown that mortality salience often leads to negative evaluations of the work of out-group members, Study 2 was designed to determine whether disparaging reactions to in-group members would emerge when salient negative information about one's in-group makes in-group identification potentially threatening to self-esteem.

To manipulate the valence of salient thoughts pertaining to Hispanic ethnicity, we had participants read a news article that described a Hispanic individual in a highly positive or negative manner. Participants next completed a questionnaire about either their own mortality or an aversive control topic (dental pain), and then indicated their preferences for abstract art that was purportedly painted by Hispanic or Anglo-American artists. We decided to include Anglo-American participants in part because our pilot testing indicated that suspicion was too high when an exclusively Hispanic group of students was in the experimental situation together. In addition, we wanted to compare Hispanic and AngloAmerican participants' responses, both to see whether the negative Hispanic prime would lead to derogation of Hispanic artists among Hispanic participants equivalent to that likely to be observed among Anglos (as in past research on the effects of mortality salience on out-group evaluations) and also to see whether the threat to the self-esteem of Hispanic participants posed by the negative Hispanic prime would lead to even higher levels of derogation of Hispanic artists than that observed among Anglo participants.

\section{Method}

Participants and design. Thirty-four male and 57 female introductory psychology students at the University of Arizona participated in partial fulfillment of a course research requirement. Hispanic and Anglo participants were recruited on the basis of a mass screening conducted earlier in the semester in which they indicated their ethnicity. The design of the study was a 2 (participant ethnicity: Hispanic vs. Anglo) $\times 2$ (prime: positive vs. negative) $\times 2$ (salience: mortality vs. dental pain) $\times 2$ (target: Hispanic vs. Anglo) mixed-model factorial, with target as a within-subject variable. Each experimental session consisted of 3 to 5 participants with approximately equal numbers of Hispanic and Anglo participants, who were randomly assigned to conditions. In debriefing, 4 participants reported 
suspicion about the procedures or hypotheses and were therefore dropped before the data were analyzed.

Procedure. On arriving at the laboratory, the experimenter, who was blind to prime and salience conditions, informed participants that they would be doing two short unrelated studies. The "first study" was described as investigating personality characteristics and how they relate to reading comprehension. Participants were told they would read a couple of news articles and a short story and complete a packet of various personality questionnaires. In the "second study," participants were told we were pretesting materials to be used for a study on artistic preferences and that they would therefore make judgments about some paintings. Similar steps to those taken in Study 1 were taken to facilitate feelings of anonymity and privacy.

The experimenter then ushered participants to their cubicles and, after having them read and sign a consent form, administered the packet of materials for "Study 1." In the packet, two filler questionnaires were followed first by a filler news article describing analog and digital radio transmissions and then by the article that constituted the prime manipulation. The negative prime was an excerpt from a Los Angeles Times article entitled, "Mexican Drug Cartel Chief Convicted in U.S.," which described the conviction of noted drug smuggler, Juan Garcia Abrego. The positive prime article was also from the Los Angeles Times, of approximately the same length. It was entitled "Making a Difference One Family at a Time" and described the charitable work of Modesto Leon, a missionary who helped build social service networks in inner cities. The next page of the packet contained three questions that were intended to buttress the cover story of our interest in participants' perceptions of the articles but that did not provide an opportunity for participants to defuse the threat posed by the article. The questions asked which of the two articles took them longer to read and how interesting they found each of the articles (both on 9-point scales).

Participants then completed the same mortality salience or dental pain salience questionnaire used in Study 1, followed by the Positive and Negative Affective Schedule-expanded form (PANAS-X; Watson \& Clark, 1992), to assess affect. Although TMT effects have consistently not been found to involve negative affect, given the novel inquiries of the present studies, we included this measure. To provide a delay before assessment of the dependent measures (cf. Greenberg, Arndt, Simon, Pyszczynski, \& Solomon, 2000), we concluded the packet with a sevenpage passage from Albert Camus's Exile in the Kingdom (1957), which has been used in previous terror management research because it is mundane and makes no reference to death and existential issues.

The experimenter then entered each cubicle with the materials for the "second study," a packet of six numbered, abstract paintings. The paintings were color copies of contemporary art postcards obtained from local galleries. The caption beneath each painting contained the title of the piece as well as the artist's name. For four of the six paintings, the artist had an Anglo name ("Susan Joyner," "Brett Malloy," "Steven Gilbert," and "Scott Richards"), and for the other two paintings, the artist had a Hispanic name ("Maria Garcia" and "Francisco Risendez"). We opted for the four-two split so as to avoid the possible suspicion that a three-three split might arouse. The pairing of artist name and painting, as well as the order in which they were presented, was counterbalanced. Participants were also given six rating sheets whose top line listed the painting number, followed by "Title: __ " and "Artist:___ Participants were told that we were pretesting a number of different paintings and that they should therefore write down the painting title and artist's name before answering the evaluation questions. In this way, we could be sure that participants were aware of the ethnicity of the artist when they made their evaluations. The rating sheet contained four questions: "How much do you like this painting?," "How interested would you be in owning this painting?," "How skillful do you think this artist is?," and "How creative do you think this artist is?" All ratings were made on 9-point scales, where 1 represented the negative anchor and 9 represented the positive anchor. After participants completed their ratings of all six artists, they returned to the main room where they were thoroughly debriefed.

\section{Results}

Evaluations of paintings. ${ }^{2}$ Our primary dependent measure was participants' ratings of the different paintings. To analyze this measure, we constructed evaluation composites that averaged responses to the four questions for each of the two Hispanic paintings and each of the four Anglo paintings, respectively (all alphas $>.89$ ). We then subjected these scores to a 2 (participant ethnicity: Hispanic vs. Anglo) $\times 2$ (prime: positive vs. negative) $\times 2$ (salience: mortality vs. dental pain) $\times 2$ (target: Hispanic vs. Anglo) ANOVA, with the last factor as a within-subject variable. This analysis revealed main effects for prime and target, both $F \mathrm{~s}(1,83)>13.00, p \mathrm{~s}<.01$, and the following two-way interactions: Salience $\times$ Prime, Prime $\times$ Target, and Prime $\times$ Participant Ethnicity, all $F \mathrm{~s}(1,83)>14.00, p \mathrm{~s}<.01$. With the exception of the Prime $\times$ Participant Ethnicity interaction, all of the aforementioned effects were qualified by the three-way interaction of Prime $\times$ Salience $\times$ Target, $F(1,83)=17.90, p<.01 .^{3}$ Cell means for this three-way interaction are presented in Table 2. Of note, the four-way interaction involving participant ethnicity was not significant $(F<1)$, indicating that the ethnicity of participants did not influence the pattern of results obtained from the three-way interaction.

To explore this three-way interaction, we conducted a series of pairwise comparisons. These comparisons indicated that after be-

\footnotetext{
${ }^{2}$ Initial analyses for this study and for Study 3 included gender as a variable, but because no significant effects were found, it is not discussed further. To buttress our cover story that we were interested in their reactions to media information, we asked participants how interesting they found the two articles after they read them. We analyzed their responses to both of these questions by means of 2 (participant ethnicity) $\times 2$ (prime) ANOVAs (mortality salience was not included because this manipulation was administered after participants responded to these questions). With regard to how interesting they found the neutral article, only a marginal main effect for prime condition approached significance, $F(1,83)=3.14$, $p=.08$ (all other $p s>.13$ ), which reflected greater interest among positive-prime $(M=5.15, S D=2.35)$ than negative-prime participants $(M=4.29, S D=2.21)$. In light of the effect described below, this appears to reflect a contrast effect. That is, negative-prime participants $(M=5.96$, $S D=1.72$ ) reported greater interest in the second, prime article than did positive-prime participants $(M=4.92, S D=2.03), F(1,83)=7.32, p<$ .01 . Thus, by comparison with the second article, the neutral-prime article may have seemed less interesting to negative-prime participants. There was also a main effect for participant ethnicity, $F(1,83)=6.28, p<.02$, which reflected greater interest reported by Hispanic $(M=5.93, S D=1.91)$ than Anglo participants $(M=5.00, S D=1.81)$.

${ }^{3}$ The Prime $\times$ Participant Ethnicity interaction reflected more positive evaluations of the paintings regardless of the artist's ethnicity by Hispanic participants after the positive ethnic prime relative to positive-prime Anglo participants and negative-prime Hispanic participants (both $t \mathrm{~s}[83]>2.43$, $p s<.05$ ), and also more negative evaluations of the paintings by negativeprime Hispanic participants than negative-prime Anglo participants, $t(83)=2.52, p<.05$. However, because this effect did not involve mortality salience or target, it is not central to our present concerns and is not discussed further.
} 
Table 2

Cell Means for the Prime $\times$ Salience $\times$ Target Interaction on Painting Evaluations in Study 2

\begin{tabular}{cccccc}
\hline & \multicolumn{2}{c}{ Mortality salient } & & \multicolumn{2}{c}{ Dental pain salient } \\
\cline { 2 - 3 } Target & $\begin{array}{c}\text { Positive } \\
(n=23)\end{array}$ & $\begin{array}{c}\text { Negative } \\
(n=23)\end{array}$ & & $\begin{array}{c}\text { Positive } \\
(n=25)\end{array}$ & $\begin{array}{c}\text { Negative } \\
(n=22)\end{array}$ \\
\hline $\begin{array}{c}\text { Hispanic } \\
M\end{array}$ & & & & & \\
$S D$ & 1.48 & 3.33 & & 5.39 & 5.00 \\
Anglo & 1.38 & 1.26 & & 1.16 & 1.24 \\
$M$ & 5.73 & 5.41 & & 5.52 & 5.59 \\
$S D$ & 1.16 & 1.47 & & 1.00 & 1.32 \\
\hline
\end{tabular}

Note. Lower numbers reflect more negative evaluations of the paintings.

ing exposed to the negative prime and then thinking about their mortality, participants were more negative in their evaluations of the Hispanic paintings than were participants' in all other conditions, all $t \mathrm{~s}(83)>5.90, p \mathrm{~s}<.01$. In contrast, after being exposed to the positive prime and then thinking about their mortality, participants were more positive in their evaluations of the Hispanic paintings relative to all other conditions, all $t \mathrm{~s}(83)>2.80, p<.05$. Thus, the combination of prime and mortality salience clearly affected how participants reacted to the Hispanic paintings in a manner that supported our hypotheses. Specifically, when participants were primed with negative thoughts about Hispanic culture, mortality salience led them to be more negative toward Hispanic paintings, but when they were primed with positive thoughts about Hispanic culture, mortality salience led them to be more positive toward such paintings. It is interesting to note that the juxtaposition of these primes with mortality salience did not affect how participants reacted to the Anglo paintings and also did not differentially affect Hispanic and Anglo participants. Consistent with the lack of the four-way interaction, when the evaluations of Hispanic and Anglo participants were analyzed separately, 2 (prime) $\times 2$ (salience) $\times 2$ (target) ANOVAs revealed significant three-way interactions for both Hispanic and Anglo participants, both $F \mathrm{~s}(1,40$ or 1,43$)>7.81, p \mathrm{~s}<.01$.

Secondary analyses. The PANAS-X (Watson \& Clark, 1992) is composed of 13 subscales measuring positive and negative mood, fear, attentiveness, hostility, shyness, fatigue, guilt, happiness, self-assuredness, sadness, serenity, and surprise. With the present data, all alphas were greater than .68 . Because the positive and negative mood scales are composed of items that also contribute to the other subscales, we conducted 2 (participant ethnicity) $\times 2$ (prime) $\times 2$ (salience) ANOVAs on the positive and negative mood subscales and a parallel multivariate analysis of variance (MANOVA) on the 11 remaining subscales. With one exception, there were no significant main effects or interactions in any of these analyses (all $F \mathrm{~s}<1.56, p \mathrm{~s}>.21$ ). The one exception was a main effect for participant ethnicity on positive mood, $F(1$, $83)=4.86, p<.04$, which reflected greater positive mood reported by Hispanic $(M=2.79, S D=0.74)$ than Anglo participants $(M=2.47, S D=0.63)$. Thus, despite leading participants to disparage Hispanic paintings, there was no indication that the prime and mortality salience influenced self-report affect. ${ }^{4}$

\section{Discussion}

The results of Study 2 support our hypothesis that mortality salience leads to less favorable evaluations of paintings by members of a group if negative exemplars of that group have been primed and leads to more favorable evaluations of paintings by members of a group if positive exemplars of that group have been primed. This pattern of results was found only on evaluations of the paintings by Hispanic artists; evaluations of the paintings by Anglo artists were not affected by the manipulations, presumably because the ethnic prime was directed only at Hispanic group identity. Thus, the differential evaluations of the Hispanic artists that occurred in the mortality-salient-negative and -positiveHispanic-prime conditions were specific to ratings of the artwork of Hispanics and do not reflect a general evaluative bias toward anything that was encountered after these manipulations. Evaluations of the work of members of a group were influenced by salient positive and negative information about an unrelated member of that group when participants' needs for existential security were heightened by reminders of their own mortality.

Whereas previous studies have shown that mortality salience can lead people to derogate members of groups to which they do not belong, the present findings demonstrate that mortality salience can also lead to derogation of members of one's own group, under certain conditions. The present findings further demonstrate that situational factors, such as recently primed information about members of a group, can influence the way mortality salience affects people's evaluations of both in-groups and out-groups. Whereas mortality salience led participants, regardless of their own ethnicity, to evaluate the work of Hispanic artists more negatively when negative information about that group had recently been primed, it led participants, again regardless of their ethnicity, to evaluate the work of Hispanic artists more positively when positive aspects of that group had been primed.

We think that these findings are particularly significant because they demonstrate conditions under which people actively derogate members of their own ethnic group, a phenomenon often discussed but rarely before demonstrated (one exception-the black sheep phenomenon-is considered below). Given the prevalence of negative stereotypes of ethnic minorities in the United States (Devine, 1989), it might not be surprising that some individuals in these groups accept some of these negative beliefs (cf. S. Steele, 1990). Furthermore, as Jost and colleagues have argued (e.g., Jost, 1995), this may sometimes result from the need to justify the dominant social system. However, in this research, only a combination of a negative framing of the group and mortality salience led to derogation of the in-group, strongly implicating a self-esteem (or, in Allport's terms, ego defensive) motive for the derogation.

Another line of research that has uncovered conditions under which people may derogate an in-group member is work on the black sheep effect. The idea underlying this work is that because of the importance of a positive social identity, people will tend to react extremely negatively to in-group members who perform very poorly or are very unlikable (e.g., Marques \& Yzerbyt, 1988). This

\footnotetext{
${ }^{4}$ A number of TMT articles extensively discuss why negative affect is not involved with mortality salience effects. For an overview of this issue, see Greenberg et al. (1997).
} 
work could also be seen as motivated by a desire to sustain self-esteem because the black sheep is a threat to deriving selfesteem from the shared social identity. However, the current finding is quite different from the fascinating black sheep phenomenon because the people being reacted to negatively in Study 2 (and being distanced from in Study 3) do not display negative characteristics; in fact, in Study 2, they are accomplished artists.

Although we feel in-group derogation is the most interesting finding of this study, it is important to keep in mind that the effects of mortality salience and ethnic prime on evaluations of the Hispanic artists were the same for both Hispanic and Anglo participants. The fact that these effects were not moderated by participants' ethnicity raises the question of whether the processes through which these effects emerged were the same or different for the two ethnic groups. The primary goal of this research was to determine whether mortality salience prompts disidentification with one's in-group when negative information about that group is salient. Whereas the negative evaluations of the Hispanic artists may well reflect such a disidentification process among the Hispanic participants in Study 2, it clearly could not have been the process responsible for the effects observed on evaluations of the Hispanic artists' paintings by the Anglo participants; such individuals had no reason to identify with the Hispanic artists or gain or lose self-esteem by virtue of such identification. It seems more plausible that among Anglo participants, mortality salience increased positive reactions toward the Hispanic artists after the positive prime because this depicted Hispanics as upholding mutual cultural values. Similarly, among Anglo participants, mortality salience may have increased negative reactions toward Hispanic culture after the negative prime because this depicted Hispanics as violating cultural standards.

From a TMT perspective, prejudice and discrimination against out-groups results both from the threat to one's cultural worldview posed by those with different beliefs and values and from the boost to both individual and collective self-esteem that results when others are seen as inferior to oneself or one's group. The finding that mortality salience led Anglos to evaluate Hispanic artists more negatively when reminded of a Hispanic individual who violates cultural values but to evaluate Hispanic artists more positively when reminded of a Hispanic individual who upholds mutual values is highly consistent with this perspective. The present findings add to previous terror management research by showing that the prejudice-increasing effects of mortality salience found in many previous studies can be attenuated and even reversed when instances of behavior supporting values shared by the two groups are salient. It appears that in the absence of information regarding shared values (e.g., Greenberg et al., 1990; Ochsmann \& Mathay, 1996), and when information emphasizing violation of these values is salient (as in the present study), mortality salience leads to derogation of out-group members. However, when information about out-group members living up to shared values is salient, mortality salience can actually lead to more positive evaluations of out-group members. Although this was not the primary focus of the present research, the potential prejudice-reducing impact of such inductions may be an encouraging avenue for future research.

The primary goal of the present research was to show that when self-esteem needs are increased because of mortality salience, information that highlights the possible negative implications of group identification for self-esteem leads to a disidentification with one's in-group, reflected in the present study by more negative evaluations of members of one's group. However, because negative evaluation of one's in-group is a rather indirect way of assessing disidentification, other explanations are also possible. The fact that similar patterns of results were found for both Hispanic and Anglo participants also raises questions about this explanation. For example, it may be possible to interpret the results from both Hispanic and Anglo participants as reflecting the same stereotyped evaluations of Hispanic individuals prompted by mortality salience and a positive or negative ethnic prime (cf. Schimel et al., 1999). Regardless of the precise mechanism through which these results emerged, however, the findings of Study 2 are the first to demonstrate that mortality salience can lead to more negative evaluations of one's own group when negative information about one's group is salient. If these negative impressions of one's group then become problematic for maintaining self-esteem, we would expect individuals to actively distance themselves from the group under such conditions. We assess this hypothesis in Study 3 by using a more direct measure of psychological distancing from the group that would be expected to yield different findings for in-group and out-group participants.

\section{Study 3}

To this end, we adapted a measure of defensive distancing in which participants rate themselves and another person with undesirable characteristics on a series of moderately desirable and undesirable personality traits; the absolute value of the difference between self and other ratings is then taken as a measure of defensive distancing. Previous studies have shown that people distort their personality ratings on this measure to appear different from those who exhibit various behavioral tendencies or characteristics they fear in themselves (e.g., Pyszczynski et al., 1993; Schimel, Pyszczynski, Greenberg, O’Mahen, \& Arndt, 2000). Here we modified this procedure to measure participants' distancing from both a Hispanic and an Anglo individual in the same experimental context. Participants first indicated their own personality and subsequently rated Anglo and Hispanic targets on the same measure.

Study 3 also enabled us to clarify a few other issues from the previous studies. First, because Study 2 included only a positive or a negative ethnic prime, it could be that the positive Hispanic prime pushed participants to react more positively, the negative Hispanic prime pushed participants to react more negatively, or both. A neutral-prime condition enabled us to address this question in Study 3. Another problem with Study 2 was that because we did not include manipulation checks, it is not entirely clear that the articles were indeed viewed positively or negatively by participants. Checks on this manipulation were included in Study 3.

The in-group disidentification hypothesis implies that mortality salience should lead Hispanic participants to distance from a Hispanic individual when they are primed to think about Hispanic culture in a negative light. However, when Hispanic participants are primed to think about Hispanic culture in a positive light, they should have less of a tendency to distance from the Hispanic individual and might even see themselves as more similar to the Hispanic target. Because Study 3 used a more direct measure of 
disidentification than that used in Study 2 (i.e., psychological distancing rather than general evaluations), if concerns with the negative implications of group identification for self-esteem are indeed responsible for these effects, only Hispanic participants should exhibit the predicted pattern.

\section{Method}

Participants and design. Sixty-two male and 69 female introductory psychology students at the University of Arizona participated as partial fulfillment of a course research requirement. As in Study 2, Hispanic and Anglo participants were recruited on the basis of mass screening information obtained earlier in the semester. Hispanic and Anglo participants were randomly assigned to conditions in a 3 (prime: positive vs. neutral vs. negative) $\times 2$ (salience: mortality vs. dental pain) $\times 2$ (target: Hispanic vs. Anglo) mixed-model factorial design, with the last factor within subject. Each experimental session again consisted of 3 to 5 participants with approximately equal numbers of Hispanic and Anglo participants. In debriefing, 3 participants reported suspicion about the procedures or hypotheses and 3 participants did not follow instructions; all 6 were dropped before the data were analyzed.

Procedure. The experimenter, who was blind to prime and salience conditions, explained that the study would investigate the relationship between personality characteristics and impressions formed from different types of information. Participants were told that they would complete some personality questionnaires, read a newspaper article and make judgments about the person featured in the article, and then read some autobiographical statements and make judgments about the people who wrote them. Participants completed all materials in private cubicles and put all their materials in blank envelopes.

Our measure of distancing from particular targets was patterned after one developed by Pyszczynski et al. (1993) and Schimel et al. (2000), with some adjustments to accommodate our desire to investigate participants' distancing from two targets rather than one. First, participants completed the Personal Assessment Questionnaire (PAQ), which entailed rating themselves on 28 traits (14 traits on each of two different pages) taken from Alicke's (1985) list of 362 trait adjectives that had been previously rated as moderately desirable or moderately undesirable (e.g., prudent, bold, restless, clumsy) and were not relevant to stereotypes of Hispanics. Using traits that were only moderately desirable or undesirable made it feasible for participants to distance themselves from the target in either direction; viewing oneself as having or not having these traits seems unlikely to impinge on self-esteem. Beneath each trait was a 100-point scale that consisted of vertical lines demarcating each of the 100 points. Participants were instructed to simply circle one line on each trait's scale that reflected how much they thought they possessed that trait. Participants were instructed to place this form in a blank envelope after completing it.

When participants finished the PAQ, the experimenter gave them a packet that contained the critical prime, the mortality salience or control treatment, and some filler personality questionnaires. The positive- and negative-prime articles were the same articles used in Study 2, except in this study they were reformatted to look more similar (e.g., number of columns, font size). We modified an additional article, also from the Los Angeles Times, to serve as our neutral prime. This article described an unusual pattern of duck migration to a local pond that was first spotted by Enrique Pasquez as he strolled through the park. After reading the article, participants completed a filler questionnaire, the same mortality salience or dental pain treatment used in Studies 1 and 2, and then another filler item.

When all participants had finished this packet, the experimenter began frantically shuffling through some papers in the main room. After a couple of minutes, the experimenter informed participants that in a previous study, we had asked people to write briefly about some different things they had experienced and that we were now going to have them read a couple of these autobiographical statements and form impressions of the people. The experimenter remarked, however, that she was having difficulty finding the impression rating forms and that she was going to run next door to look for more forms in her office. After $3 \mathrm{~min}$, the experimenter returned and said that she was unable to find the appropriate forms but that while she was looking she had an idea about how to overcome this oversight. The experimenter explained that the rating form they were supposed to use was actually quite similar to the first personality form (PAQ) on which participants had rated themselves. Thus, as a solution to the current dilemma, participants were instructed to take their PAQ from the envelope and make their ratings of the target persons on this form. Specifically, participants were asked to rate the first person they had read about on the first page of the form, and the second person they had read about on the second page of the form. Whereas participants had previously indicated their ratings of themselves by circling a line on each trait's scale, they were now asked to rate the target persons by placing an " $\mathrm{X}$ " over a particular line. This ploy enabled us to keep the participants' own ratings on the various traits salient while they rated the target's. The experimenter then remarked that "so we can be sure which is which," participants should write the name of the person they were evaluating on top of each page of the PAQ. In this way, we ensured that participants were aware of the targets' ethnicity. Participants were then given the autobiographical statements, and the instructions were reiterated.

The biographical description form for each target listed the target's name, gender, level of education (college sophomore), and then a brief paragraph describing what they did over the past summer. Participants always received statements by two people of the same gender as themselves. For female participants, the names of the targets were Emily Garcia and Nancy Johnson, for the male participants, the names of the targets were Robert Garcia and Mark Thomas. The paragraphs were both relatively mundane and described typical summer activities of a college student (e.g., traveling to visit friends and family, a summer job). Which target (Hispanic or Anglo) was paired with which paragraph and the order in which they were evaluated (and thus the traits on which they were rated) were counterbalanced.

After rating the targets, participants completed manipulation check questions assessing the positive or negative portrayal of the Hispanic person in the news article. Participants answered questions asking, "Overall, would you say that the person in the news article was positive or negative?" and "How interesting did you find the person is the news article." Both responses were made on 9-point scales with 1 as the negative anchor and 9 as the positive anchor. Participants also rated the person in the article on four positive traits (giving, hardworking, kind, and brave) and four negative traits (lazy, selfish, cowardly, and mean) on 5-point scales, with 1 reflecting little of that trait and 5 reflecting much of that trait. Participants were probed for suspicion, debriefed, and compensated with research credits.

\section{Results}

Manipulation checks. To check on the effectiveness of the ethnic prime manipulation, we analyzed participants' ratings of the positivity-negativity of the person portrayed in the article. This analysis provided strong support for the effectiveness of the manipulation. A 2 (participant ethnicity) $\times 3$ (prime) $\times 2$ (salience) ANOVA revealed only a significant main effect of prime on perceptions of the person, $F(2,118)=123.72, p<.001$. Table 3 presents the means for these responses as well as the other manipulation check questions that follow. Participants in the positiveprime condition rated the person in the article as more positive than participants in the negative- or neutral-prime conditions, both 
Table 3

Cell Means for the Main Effects of Prime on the Manipulation Checks in Study 3

\begin{tabular}{|c|c|c|c|}
\hline Variable & $\begin{array}{l}\text { Positive } \\
(n=44)\end{array}$ & $\begin{array}{l}\text { Neutral } \\
(n=44)\end{array}$ & $\begin{array}{l}\text { Negative } \\
(n=42)\end{array}$ \\
\hline \multicolumn{4}{|c|}{ Overall interest in the article } \\
\hline$M$ & 6.64 & 4.18 & 5.26 \\
\hline$S D$ & 1.60 & 2.16 & 2.16 \\
\hline \multicolumn{4}{|c|}{$\begin{array}{l}\text { Overall positivity of } \\
\text { Hispanic person }\end{array}$} \\
\hline$M$ & 8.20 & 6.14 & 2.93 \\
\hline$S D$ & 1.13 & 1.68 & 1.76 \\
\hline \multicolumn{4}{|c|}{$\begin{array}{c}\text { Positive trait ratings of } \\
\text { Hispanic person }\end{array}$} \\
\hline$M$ & 4.53 & 3.32 & 2.54 \\
\hline$S D$ & 0.44 & 0.76 & 0.78 \\
\hline \multicolumn{4}{|c|}{$\begin{array}{c}\text { Negative trait ratings of } \\
\text { Hispanic person }\end{array}$} \\
\hline$M$ & 1.32 & 2.12 & 3.12 \\
\hline$S D$ & 0.32 & 0.75 & 0.72 \\
\hline
\end{tabular}

Note. For overall positivity the scale ranged from 1 (very negative) to 9 (very positive). For positive and negative traits, the scales ranged from 1 (not possessing that trait) to 5 (possessing that trait).

$t \mathrm{~s}(118)>6.00, p \mathrm{~s}<.01$. The negative prime also led to more negative evaluations than the neutral prime, $t(118)=9.23, p<.01$.

Similar main effects were also found on composites that averaged participants' ratings of the person on the four positive and four negative traits, respectively (both alphas $>.76$ ), both $F \mathrm{~s}(2$, $118)>92.00, p s<.001$. Participants rated the person depicted in the positive-prime article higher on positive traits and lower on negative traits than they rated the person depicted in either the neutral- or negative-prime articles. The person depicted in the negative prime was also rated more negatively and less positively than the person depicted in the neutral prime, all $t \mathrm{~s}(118)>5.50$, $p s<.01$. Analyses of the traits, however, also revealed one significant interaction. For the positive traits, there was an unexpected Prime $\times$ Salience interaction, $F(2,118)=7.92, p<.01$. Cell means for this interaction are presented in Table 4. Although there was a similar pattern for both mortality and dental pain salient participants, mortality salient participants rated the neutral person less favorably but the negative person more favorably than

Table 4

Cell Means for the Prime $\times$ Salience Interaction on the Positive Trait Ratings of the Prime Person in Study 3

\begin{tabular}{lccc}
\hline Salience & Positive & Neutral & Negative \\
\hline Mortality & & & \\
$M$ & 4.62 & 3.02 & 2.75 \\
$S D$ & 0.45 & 0.77 & 0.62 \\
$n$ & 23 & 23 & 22 \\
Dental pain & & & \\
$M$ & 4.44 & 3.65 & 2.31 \\
$S D$ & 0.42 & 0.60 & 0.88 \\
$n$ & 21 & 21 & 20 \\
\hline
\end{tabular}

Note. Higher numbers reflect more positive trait ratings. did their dental pain counterparts, $t(118)=3.31, p<.01$, and $t(118)=2.16, p<.05$, respectively. Taken together, it appears that in the mortality salient condition, participants were less impressed with the neutral Hispanic person and more reluctant to deny positive traits to the negative Hispanic person.

We also conducted a 2 (participant ethnicity) $\times 3$ (prime) $\times 2$ (salience) ANOVA on the question asking how interesting participants found the article they had read. This revealed a main effect for prime, $F(1,118)=16.52, p<.001$, which was qualified by a Prime $\times$ Salience interaction, $F(2,118)=3.30, p<.05$. Cell means for this interaction are presented in Table 5. Pairwise comparisons showed that none of the mortality salient conditions significantly differed from their dental pain counterparts (all $t \mathrm{~s}<1.64)$. However, within the mortality salient conditions, the positive and negative articles were both viewed as more interesting than the neutral article, both $t \mathrm{~s}(118)>3.36, p \mathrm{~s}<.01$, but did not differ from each other $(t<1)$. Within the dental pain conditions, the positive article was viewed as more interesting than both the neutral and the negative article, both $t \mathrm{~s}(118)>3.78, p \mathrm{~s}<.01$, which did not differ from each other $(t<1)$. None of the effects involving participant ethnicity approached significance (all $F$ s $<$ 1). Given that these and the above ratings were obtained after participants had differentially engaged in distancing, these patterns may reflect the effect of the defensive response.

Psychological distancing. The primary dependent measure in this study was the extent of distancing from both the Hispanic and the Anglo target. Following Pyszczynski et al. (1993) and Schimel et al. (2000), we created Hispanic and Anglo distancing scores by counting the number of slashes in between participants' rating of themselves and their rating of the targets on each of the 14 traits pertaining to that target. An average distance score with respect to each target was computed by summing the absolute value of the difference between participants' self- and other ratings and dividing by the number of traits. Although we did not expect high interitem consistency because level of distancing on any given item is most likely affected by the individual's self-rating on that particular item (e.g., there is less room for distancing on items in which the individual's self-rating is moderate), Cronbach's alpha for the distancing measure was .76. We then subjected these scores to a 2 (participant ethnicity) $\times 3$ (prime) $\times 2$ (salience) $\times 2$ (target) ANOVA, with the last factor within subject. This analysis revealed a main effect for target, $F(1,119)=5.19, p<.03$, and

Table 5

Cell Means for the Prime $\times$ Salience Interaction on How Interesting the Prime Article Was in Study 3

\begin{tabular}{lccc}
\hline Salience & Positive & Neutral & Negative \\
\hline Mortality & & & \\
$M$ & 6.26 & 3.78 & 5.77 \\
$S D$ & 1.89 & 2.15 & 2.05 \\
$n$ & 23 & 23 & 22 \\
Dental pain & & & \\
$M$ & 7.05 & 4.62 & 4.70 \\
$S D$ & 1.12 & 2.13 & 2.20 \\
$n$ & 21 & 21 & 20 \\
\hline
\end{tabular}

Note. Higher numbers reflect greater interest. 
Table 6

Cell Means for Prime $\times$ Salience $\times$ Target on Distancing in Study 3 Among Hispanic Participants

\begin{tabular}{cccccccr}
\hline & \multicolumn{3}{c}{ Mortality salient } & & \multicolumn{3}{c}{ Dental pain salient } \\
\cline { 2 - 4 } Target & $\begin{array}{c}\text { Positive } \\
(n=12)\end{array}$ & $\begin{array}{c}\text { Neutral } \\
(n=12)\end{array}$ & $\begin{array}{c}\text { Negative } \\
(n=11)\end{array}$ & & $\begin{array}{c}\text { Positive } \\
(n=11)\end{array}$ & $\begin{array}{c}\text { Neutral } \\
(n=10)\end{array}$ & $\begin{array}{r}\text { Negative } \\
(n=10)\end{array}$ \\
\hline Hispanic & & & & & & & \\
$M$ & 19.76 & 23.43 & 27.53 & & 22.86 & 20.43 & 19.46 \\
$S D$ & 7.29 & 11.58 & 8.39 & & 7.52 & 9.83 & 9.40 \\
Anglo & & & & & & 18.13 & 21.41 \\
$M$ & 19.50 & 21.86 & 19.17 & & 18.91 & \\
$S D$ & 7.51 & 8.56 & 7.79 & & 7.18 & 6.41 & 9.15 \\
\hline
\end{tabular}

Note. Higher numbers reflect more distancing.

a marginal Participant Ethnicity $\times$ Prime $\times$ Salience interaction, $F(2,119)=2.65, p<.08$. Both of these effects were qualified, however, by the predicted four-way interaction between participant ethnicity, prime, salience, and target, $F(2,119)=3.34, p<$ .04. For convenience, these means appear separately for Anglo and Hispanic participants in Tables 6 and 7, respectively.

Given the significant four-way interaction and our specific hypothesis about elevated distancing among Hispanic participants in the negative-prime mortality salience condition with respect to the Hispanic target, we followed the recommendations of Rosenthal, Rosnow, and Rubin (2000) and conducted a series of planned contrasts. According to Rosenthal et al., such an approach presents a more appropriate and informative strategy of asking focused, hypothesis-driven questions of data than do omnibus tests of ANOVA. ${ }^{5}$ With the present study, there were four important between-groups contrasts, all involving negative-prime mortality salient Hispanic participants' reactions to the Hispanic target, each of which offered support for our analysis. Within the negativeprime condition, among Hispanic participants, mortality salience led to greater distancing from the Hispanic target than did dental pain salience, $t(119)=3.29, p<.01$. Among the mortality salient Hispanic participants, the negative prime led to significantly more distancing from the Hispanic target than the positive-prime mortality salience condition, $t(119)=3.22, p<.01$, and marginally more of such distancing than the neutral prime, $t(119)=1.75, p<$ .10. In addition, in the negative-prime mortality salience condition, Hispanic participants distanced more than did their Anglo counterparts, $t(119)=3.49, p<.01$. The critical within-subject contrast was between Hispanic participants' reactions to the Hispanic and Anglo target within the negative-prime mortality salient condition. As expected, within this condition, Hispanic participants distanced more from the Hispanic target than from the Anglo target, $t(119)=3.50, p<.01$. Taken together, these comparisons show that there was a unique tendency for Hispanics to distance from a fellow Hispanic in the negative-prime mortality salient condition.

Supplemental analyses. One potential alternative explanation for the present findings is that, perhaps by rating the targets less positively on the positive traits and more negatively on the negative traits than themselves, participants were not distancing from the target but rather were attempting to present a positive self- image. In each of the seven previous studies using a similar distancing measure (e.g., Pyszczynski et al., 1993; Schimel et al., 2000) there was no indication that participants were simply affirming a positive self-image but that the data reflected a general tendency for participants to see themselves as less similar to the stigmatized target persons. In the present studies, participants' rated themselves prior to the administration of any manipulation and then subsequently rated the different targets. A 2 (participant ethnicity) $\times 3$ (prime) $\times 2$ (salience) ANOVA performed on a composite measure of the positivity of participants' self-ratings ( $\alpha=.75$ ) confirmed that there were no differences between groups on self-ratings in the present study (all $F_{\mathrm{s}}<1.60, p \mathrm{~s}>.21$ ). However, there is still the possibility that presentation of a positive self might have been occurring in the present study through participants' ratings of the targets.

To investigate this possibility, we rescored participants' responses to the distancing measure for the extent to which they

\footnotetext{
${ }^{5}$ Another approach to analyzing this four-way interaction would be to break it down into lower order interactions. In these scenarios, there is a significant three-way interaction within Hispanic participants but not Anglo participants, a breakdown that perhaps makes more sense than those that follow, as participant ethnicity was the one nonmanipulated variable and we were primarily interested in the effects of the mortality salience and prime manipulations on distancing from the Hispanic as opposed to the Anglo target. However, one could also break it down within prime condition. As we would expect, in that case, the only significant three-way interactions occurred within the negative-prime condition. Or one could also break it down within target. In this case, again as we would expect, there is a significant three-way interaction for the Hispanic target but not for the Anglo target. Finally, one could also break it down within salience condition, in which case neither three-way interaction is significant. This latter option may perhaps be the least appropriate given that it misses the important comparisons between the mortality salience and dental pain conditions, which our reasoning suggests is a critical impetus behind these effects. However, we opted not to pursue any of these strategies because, as Rosenthal et al. (2000) articulated, in most cases of theoretically driven hypothesis testing, higher order interactions in ANOVA do not actually test the precise predicted pattern. They are an omnibus test that is overly broad and does not accurately represent the specific hypothesis or hypotheses. In these situations, Rosenthal et al. recommend performing planned contrasts to assess the specifically hypothesized pattern.
} 
Table 7

Cell Means for Prime $\times$ Salience $\times$ Target on Distancing in Study 3 Among Anglo Participants

\begin{tabular}{|c|c|c|c|c|c|c|}
\hline \multirow[b]{2}{*}{ Target } & \multicolumn{3}{|c|}{ Mortality salient } & \multicolumn{3}{|c|}{ Dental pain salient } \\
\hline & $\begin{array}{l}\text { Positive } \\
(n=11)\end{array}$ & $\begin{array}{l}\text { Neutral } \\
(n=11)\end{array}$ & $\begin{array}{l}\text { Negative } \\
(n=11)\end{array}$ & $\begin{array}{l}\text { Positive } \\
(n=10)\end{array}$ & $\begin{array}{c}\text { Neutral } \\
(n=11)\end{array}$ & $\begin{array}{l}\text { Negative } \\
(n=11)\end{array}$ \\
\hline \multicolumn{7}{|c|}{ Hispanic } \\
\hline$M$ & 23.52 & 17.93 & 19.19 & 16.86 & 22.70 & 20.87 \\
\hline$S D$ & 10.49 & 7.47 & 9.70 & 8.32 & 10.15 & 6.97 \\
\hline \multicolumn{7}{|l|}{ Anglo } \\
\hline$M$ & 22.01 & 17.71 & 17.75 & 18.51 & 21.50 & 19.07 \\
\hline$S D$ & 9.91 & 8.56 & 3.41 & 6.91 & 8.63 & 6.86 \\
\hline
\end{tabular}

Note. Higher numbers reflect more distancing.

rated the different targets higher on positive traits and lower on negative traits than they rated themselves; higher scores thus reflected more positive ratings of the targets than of themselves. Cronbach's alpha for this measure was .46. This low alpha may reflect the fact that we had not designed the items to measure favorability of evaluation and, in fact, intentionally used relatively moderately valenced traits. We subjected these scores to a 2 (participant ethnicity) $\times 3$ (prime) $\times 2$ (salience) $\times 2$ (target) ANOVA, with the last factor within subject. The only effect to reach significance for this analysis was a main effect for target, $F(1,119)=6.89, p=.01$, indicating that relative to themselves, participants rated the Hispanic target $(M=-4.03, S D=9.06)$ more negatively than they did the Anglo target $(M=-1.52, S D=$ $8.28)$.

It could also be suggested that the results on the composite distancing measure reflect differences in the favorability of perceptions of either the Hispanic or the Anglo target person rather than distancing. To examine this possibility, we computed composite measures of the favorability ratings given both target persons $(\alpha=.35)$ and subjected these scores to a 2 (participant ethnicity) $\times 3$ (prime) $\times 2$ (salience) $\times 2$ (target) ANOVA, with the last factor treated within subject. This analysis, too, found no significant effects (all $F \mathrm{~s}<1.10, p \mathrm{~s}>.30$ ).

\section{Discussion}

Study 3 demonstrated that mortality salience can lead to distancing from one's own ethnic group when negative information about one's group is salient, presumably because identification with one's ethnic group could undermine self-esteem (Branscombe, 1998; Doosje et al., 1998). Given the results of the subsidiary analyses, these results cannot be interpreted as reflecting simple inflation of one's self-concept, derogation of the Hispanic target person, or self-aggrandizement relative to the target persons. The subsidiary analyses also show that the combination of mortality salience and the negative prime led to high levels of distancing from the Hispanic target person relative to the Anglo target person. It seems clear that in this study, Hispanic participants psychologically distanced themselves from Hispanic but not Anglo target persons after negative behavior by a member of their in-group had been made salient and they were reminded of their own mortality.

The findings from Study 3 substantially clarify the results found in Study 2 and, in so doing, provide strong support for the hypoth- eses guiding the present research. Study 2 showed that positive and negative ethnic primes differentially affected reactions to Hispanic paintings following mortality salience and that this effect occurred among both Hispanic and Anglo participants. The results of Study 3 demonstrate that when a measure of psychological distancing rather than simple evaluation was used, the tendency to disidentify from a Hispanic target was confined to Hispanic participants. Presumably, because Anglo participants were already sufficiently different from the Hispanic target, there was no pressure to distance.

The results from Study 3 also resolve other ambiguities from the first and second studies. With regard to Study 1, Study 3 shows that mortality salience not only blocks increased identification, it can also encourage disidentification if a negative exemplar of the group is salient. With regard to Study 2, the use of a neutral-prime condition enabled us to see that although Hispanic participants clearly distanced from the Hispanic target person in response to the negative ethnic prime, there was also a nonsignificant trend for the positive prime to promote reduced distancing (or increased identification) after mortality salience. In addition, the manipulation check data revealed that the priming articles were indeed perceived as we intended them to be. The person depicted in the negativeprime article was rated as more negative than the person depicted in both the positive- and neutral-prime articles. Conversely, the person portrayed in the positive article was rated as more positive and was ascribed a more positive personality profile than the other two targets.

Although we believe that these studies provide an important new perspective on both terror management processes and group identification, there is one limitation that should be noted. In Studies 2 and 3, our Hispanic sample was composed of individuals who indicated their ethnicity as Hispanic on a mass survey screening session. However, this demographic questionnaire did not differentiate between Latino, Puerto Rican, or Mexican ethnicity. Given that the negative Hispanic prime article specifically referred to a Mexican, it is possible that this manipulation had more impact on the subset of our Hispanic sample of Mexican descent than it did on participants of other Hispanic origins. Although future research would benefit from assessing these distinctions, considering the geographical locale where these studies were conducted (Tucson, Arizona), it is likely that a vast majority of our sample were in fact Mexican Americans. Indeed, the senior research 
analyst for Multicultural Programs and Services at the University of Arizona reported that over $85 \%$ of Hispanic students at the University of Arizona are Mexican American (S. Baldinegro, personal communication, November, 1999).

\section{General Discussion}

The results of the three studies reported in this article provide consistent evidence that mortality salience can motivate individuals to reduce their identification with their in-groups when such identification has the potential to undermine their self-esteem. This tendency to respond to mortality salience with reduced in-group affiliation was documented across two very different types of social groups and with three very different dependent measures. Study 1 demonstrated that stereotype threat, which presents a potential threat to one's self-esteem (cf. C. M. Steele \& Aronson, 1995), can undermine the typical effect of mortality salience increasing in-group affiliation. In this study, mortality salience led female participants to view themselves as having more in common with most other women (as indexed by a social projection measure); this effect was completely eliminated, however, when stereotype threat was induced by an upcoming math test. In Study 2, priming an instance of negative behavior by a specific member of the Hispanic ethnic group led both Hispanic and Anglo participants to evaluate the work of Hispanic artists (who were of course different persons from the priming person) more negatively when mortality was salient. Whereas previous studies have shown that mortality salience often leads to more negative evaluations of out-group members, Study 2 showed that this tendency can extend to in-group members as well when identification with one's ingroup could reflect negatively on self. In Study 3 we used a more direct measure of identification and showed that the same negative prime used in Study 2 combined with mortality salience to lead to distancing from a Hispanic but not an Anglo target person among Hispanic but not Anglo participants. Thus, Study 3 provides the most direct evidence of active disidentification from one's ingroup. Across all three studies, mortality salience led participants to move away from their in-group when situational factors made identification with that group a potential threat to self-esteem, and the need for self-esteem was heightened by a reminder of their mortality.

Most previous theory and research on in-group affiliation has assumed that cultural and group identifications have a beneficial effect on self-esteem, and this assumption has been central to most previous terror management research on this issue. Given that the hypothesis that reminders of mortality lead to increased in-group identification has received consistent support across a number of paradigms, with various manipulations of mortality salience, measures of worldview defense, and subject populations (Greenberg et al., 1997), it would appear that this assumption is most often accurate. However, the finding that mortality salience can lead to distancing from one's in-group when the negative self-esteem implications of one's group identity are salient suggests that group affiliations can sometimes be threatening. The present findings thus provide an important clarification of the psychological mechanisms underlying mortality salience effects. As terror management theorists have consistently maintained, mortality salience effects do not reflect a simple in-group versus out-group bias; rather, the evaluative bias is toward those who validate or threaten a worldview that provides the individual with the opportunity to enhance self-esteem. More often than not, this falls along an in-group/out-group distinction, but the present findings demonstrate that this need not always be the case.

The problem of negative aspects of one's social identity undermining self-esteem may be especially problematic for groups that are stigmatized by negative stereotypes. Because members of minority groups are more frequently exposed to negative stereotypes about their groups (see e.g., Allport, 1954; C. M. Steele \& Aronson, 1995) and because they may be motivated to justify the prevailing social system (Jost, 1995), they may develop more ambivalent and tenuous identifications with their ethnic heritage. However, the work of Branscomb (1998), Doosje et al. (1998), and Stone et al. (1999) indicates that negative self-esteem implications of in-group identity also exist for dominant cultural groups. This suggests that similar disidentification tendencies may also occur among members of such groups when reminded of negative aspects or exemplars of their group.

\section{Implications for Understanding the Relationship Between Needs for Belonging and Self-Esteem}

These findings have implications for the viability of the sociometer model as a parsimonious explanation for the self-esteem motive and its relations to social connections (Leary \& Downs, 1995; Leary, Tambor, Terdal, \& Downs, 1995). A number of historical and contemporary perspectives within social psychology have discussed the relationship between belonging and selfesteem, typically suggesting that belonging serves self-esteem (e.g., social identity theory). However, in recent years, Leary and colleagues (e.g., Leary \& Downs, 1995; Leary et al., 1995) have proposed a sociometer model that posits people are primarily motivated to belong to groups and that self-esteem serves merely as an indicator of the extent to which they are successfully meeting this goal. Thus, from the sociometer perspective, the need for self-esteem is largely epiphenomenal and subordinate to a more basic need to belong. However, if the need for self-esteem were really subservient to a need to belong, it would be hard to explain why the negative self-esteem implications of group membership would lead people to distance themselves from their in-groups. Although social connections are certainly an important aspect of human social behavior, the present findings, as well as other lines of research (e.g., Branscomb, 1998; Cialdini et al., 1976; Deschene et al., 2000; Doosje et al., 1998; Greenwald et al., 1999; Schimel et al., 2000; Snyder et al., 1986; Spears et al., 1997; Tesser, 1988), clearly indicate that there are situations in which people strive to minimize belonging to particular groups, even those likely to be extremely important to them, such as gender and ethnicity. The present studies show that people disengage from important group identities when affiliation with that group is likely to reflect negatively on self-esteem and the need for self-esteem is heightened by reminders of one's mortality. This suggests that one's sense of belonging or not belonging to groups may serve selfesteem and its underlying existential function. From a terror management perspective, associations with others are an important means of maintaining psychological equanimity; however, this is 
true only when that sense of belonging helps to validate one's worldview or one's self-esteem.

\section{Worldview Defense or Disidentification?}

The present research raises the important question of when an individual will defend his or her worldview and when he or she will opt to distance from it. In research documenting the former response, researchers typically expose participants to negative attacks on their beliefs (e.g., American participants reading an essay that berates the United States) and observe increased derogation of the source of this attack following mortality salience. In the present studies, participants were exposed to negative exemplars of their cultural group, and mortality salience led them to devalue their group in Study 2 and distance themselves from that group in Study 3, rather than affirm their identification by defending their group. However, in the current studies, unlike past research, participants were offered no opportunity to defend against the threat to their group. Perhaps the opportunity to defend against the negative implications of group membership would negate the tendency to disidentify.

Another way of thinking about the question of worldview defense or disidentification is by considering the different types of justifications that Jost and Banaji (1994) refer to as egojustification (protection of self), group justification (protection of the group), and system justification (protection of the prevailing social system). From this perspective, one may ask what is it that mortality salience triggers? We suggest that mortality salience motivates the need to maintain the dual components of the cultural anxiety buffer: self-esteem and faith in a meaningful worldview. To the extent that these three types of justification can buttress the cultural anxiety buffer, mortality salience may at times increase each type of justification. If this is the case, the interesting question then concerns which motive will predominate under what conditions. Both the present studies and previous research suggest a number of important factors that play a role.

From our perspective, the individual's levels of investment in particular aspects of self, groups, and social systems for meaning and self-worth play an important role, as do situational factors that threaten or make salient particular aspects of self, group identifications, or systems. For example, the centrality of the group identity that is under threat may be an important moderator of whether one's group identity is defended (or justified) or denied in such circumstances. The more an individual's self-worth depends on a certain group identity, the more likely he or she should be to defend that identification (Doosje, Ellemers, \& Spears, 1995). Indeed, when individuals are highly invested in a system of beliefs, attacks on those beliefs often engender even stronger commitment to that dogma (Batson, 1975; Festinger, Riecken, \& Schachter, 1956).

Recent terror management findings are consistent with this view. For example, although high self-esteem typically buffers individuals from the need for worldview defense following mortality salience (Harmon-Jones et al., 1997), when the worldview threat undermines the basis from which that high self-esteem is derived, participants respond defensively by derogating the threat (Arndt \& Greenberg, 1999). Research has also shown that in the face of threats to group status, those who are more weakly iden- tified with the group will distance themselves from the group whereas those who are more strongly identified will not (e.g., Doosje et al., 1995; Spears et al., 1997; Wann \& Branscomb, 1990). Indeed, Spears et al. (1997) found that high group identifiers showed a tendency to increase self-stereotyping after threat, that is, to increase their perception of themselves as a prototypical group member. It also appears important to consider the extent to which the individual has alternative group identifications to which he or she can turn and the extent to which the individual feels "locked in" to that particular identification. For example, in Dechesne, Greenberg, et al. (2000), after mortality salience, university students shifted their identification from a currently losing football team to a championship basketball team.

In addition, Dechesne, Janssen, and van Knippenberg (2000) found that perceived permeability of the group identification is an important factor. Specifically, after exposure to subliminal death primes, students led to believe that university identification is relatively permanent derogated a critic of their university and did not disidentify from the school. In contrast, death primed students who were led to believe that university identification is temporary and changeable reduced identification with the school and did not derogate the critic.

A related factor that may influence reactions to group identity is the need for structure. Dechesne, Janssen, and Van Knippenberg (2000) proposed that disidentification is most likely in those low in need for structure, whereas people high in need for structure, for whom group identification may be more important, may be more likely to defend against the negative view of the group. In support of these ideas, they found that high-need-for-structure participants exposed to subliminal death primes derogated a critic of their local university and did not disidentify, whereas low-need-for-structure participants exposed to the primes decreased identification with their university after reading the critical opinion and did not derogate the critic. In the present studies, we did not give the participants the opportunity to refute the negative image conveyed by the newspaper article; the Dechesne et al. work suggests that if we had, perhaps less disidentification would have occurred. On the other hand, to the extent that the article used in the present studies made salient a widely known negative stereotype of the group, as opposed to a single individual's criticism of a highly culturally valued university, as in Dechesne et al., this may have been more difficult for the participants in the present research to accomplish. Thus, although important inroads have been made to understanding the specific motivations provoked by thoughts of death under particular conditions, more research is clearly needed.

\section{Conclusion}

On the basis of the findings of this research, it appears that association with the groups to which we belong may not always be a source of pride and security. Although most people do not conform to the negative stereotypes associated with their group and have not participated in the evildoings of other members of their group, all people may feel some vulnerability to the negative implications these actions have for their sense of self-worth. Unfortunately, some social identities may more deeply or frequently threaten self-esteem than others. Members of groups that are associated with many negative stereotypes are likely to face 
greater challenges to maintaining a security-providing positive social identity. The research reported here suggests that when terror management needs are particularly high, one way people deal with this dilemma is by strategically distancing themselves from their heritage. However, such action may also have the unfortunate consequence of separating people from the long-term self-esteem and security benefits that one's group identity can provide, creating a particularly difficult problem for those with minority group identifications. Clearly, further progress is needed toward understanding how members of such stigmatized groups can optimize their social and personal identifications for an enduring security-providing sense of self-worth.

\section{References}

Alicke, M. D. (1985). Global self-evaluation as determined by the desirability and controllability of trait adjectives. Journal of Personality and Social Psychology, 49, 1621-1630.

Allport, G. W. (1954). The nature of prejudice. New York: Doubleday. Arndt, J., \& Greenberg, J. (1999). The effects of a self-esteem boost and mortality salience on responses to boost relevant and irrelevant worldview threats. Personality and Social Psychology Bulletin, 25, 13311341.

Arndt, J., Greenberg, J., Solomon, S., Pyszczynski, T., \& Schimel, J. (1999). Creativity and terror management: The effects of creative activity on guilt and social projection following mortality salience. Journal of Personality and Social Psychology, 77, 19-32.

Batson, C. D. (1975). Rational processing or rationalization? The effects of disconfirming information on a stated religious belief. Journal of Personality and Social Psychology, 32, 176-184.

Becker, E. (1973). The denial of death. New York: Free Press.

Bettelheim, B. (1943). Individual and mass behavior in extreme situations. Journal of Abnormal and Social Psychology, 38, 417-452.

Biernat, M., Vescio, T. K., \& Green, M. L. (1996). Selective selfstereotyping. Journal of Personality and Social Psychology, 71, 11941209.

Branscomb, N. R. (1998). Thinking about one's gender group's privileges and disadvantages: Consequences for well-being in women and men. British Journal of Social Psychology, 37, 167-184.

Brewer, M. B. (1991). The social self: On being the same and different at the same time. Personality and Social Psychology Bulletin, 17, 475482.

Butcher, J. N., Dahlstrom, W. G., Graham, J. R., Tellegen, A., \& Kaemmer, B. (1989). MMPI-2 manual for administration and scoring. Minneapolis: University of Minnesota Press.

Camus, A. (1957). Exile and the kingdom. New York: Vintage Books.

Child, I. L. (1943). Italian or American? New Haven: Yale University Press.

Cialdini, R. B., Borden, R. J., Thorne, A., Walker, M. R., Freeman, S., \& Sloan, L. R. (1976). Basking in reflected glory: Three (football) field studies. Journal of Personality and Social Psychology, 34, 366-375.

Clark, K., \& Clark, M. (1947). Racial identification and preference in Negro children. In T. M. Newcomb \& E. L. Hartley (Eds.), Readings in social psychology (pp. 169-178). New York: Holt.

Crocker, J., \& Major, B. (1989). Social stigma and self-esteem: The self-protective properties of stigma. Psychological Review, 96, 608630.

Crocker, J., Voelkl, K., Testa, M., \& Major, B. (1991). Social stigma: The affective consequences of attributional ambiguity. Journal of Personality and Social Psychology, 60, 218-228.

Deaux, K. (1993). Reconstructing social identity. Personality and Social Psychology Bulletin, 19, 4-12.
Dechesne, M., Greenberg, J., Arndt, J., \& Schimel, J. (2000) Terror management and sports fan affiliation: The effects of mortality salience on fan identification and optimism. European Journal of Social Psychology, 30, 813-835.

Dechesne, M., Janssen, J., \& van Knippenberg, A. (2000). Defense and distancing as terror management strategies: The moderating role of need for structure and permeability of group boundaries. Journal of Personality and Social Psychology, 79, 923-932.

Dechesne, M., Pyszczynski, T., Ransom, S., Arndt, J., Sheldon, K. M., \& Janssen, J. (2001). Literal and symbolic immortality: The effects of evidence of literal immortality on self-esteem striving in response to mortality salience. Manuscript submitted for publication, University of Nijmegen, the Netherlands.

Devine, P. (1989). Stereotypes and prejudice: Their automatic and controlled components. Journal of Personality and Social Psychology, 56, $5-18$.

Doosje, B., Branscombe, N. R., Spears, R., \& Manstead, A. S. R. (1998). Guilty by association: When one's group has a negative history. Journal of Personality and Social Psychology, 75, 872-886.

Doosje, B., Ellemers, N., \& Spears, R. (1995). Perceived intragroup variability as a function of group status and identification. Journal of Experimental Social Psychology, 31, 410-436.

Ethier, K. A., \& Deaux, K. (1994). Negotiating social identity when contexts change: Maintaining identification and responding to threat. Journal of Personality and Social Psychology, 67, 243-251.

Festinger, L., Riecken, H. W., \& Schachter, S. (1956). When prophecy fails. Minneapolis: University of Minnesota Press.

Florian, V., \& Mikulincer, M. (1997). Fear of death and the judgment of social transgressions: A multidimensional test of terror management theory. Journal of Personality and Social Psychology, 73, 369-380.

Florian, V., \& Mikulincer, M. (1998). Terror management in childhood: Does death conceptualization moderate the effects of mortality salience on acceptance of similar and different others? Personality and Social Psychology Bulletin, 24, 1104-1112.

Goldenberg, J. L., McCoy, S. K., Pyszczynksi, T., Greenberg, J., \& Solomon, S. (2000). The body as a source of self-esteem: The effects of mortality salience on identification with one's body, interest in sex, and appearance monitoring. Journal of Personality and Social Psychology, 79, 118-130.

Greenberg, J., Arndt, J., Simon, L., Pyszczynski, T., \& Solomon, S. (2000). Proximal and distal defenses in response to reminders of one's mortality: Evidence of a temporal sequence. Personality and Social Psychology Bulletin, 26, 91-99.

Greenberg, J., Pyszczynski, T., \& Solomon, S. (1986). The causes and consequences of a need for self-esteem: A terror management theory. In R. F. Baumeister (Ed.), Public self and private self (pp. 189-212). New York: Springer-Verlag.

Greenberg, J., Pyszczynski, T., Solomon, S., Pinel, E., Simon, L., \& Jordan, K. (1993). Effects of self-esteem on vulnerability-denying defensive distortions: Further evidence of an anxiety-buffering function of self-esteem. Journal of Experimental Social Psychology, 29, 229-251.

Greenberg, J., Pyszczynski, T., Solomon, S., Rosenblatt, A., Veeder, M., Kirkland, S., \& Lyon, D. (1990). Evidence for terror management: II. The effects of mortality salience on reactions to those who threaten or bolster the cultural worldview. Journal of Personality and Social Psychology, 58, 308-318.

Greenberg, J., Simon, L., Porteus, J., Pyszczynski, T., \& Solomon, S. (1995). Evidence of a terror management function of cultural icons: The effects of mortality salience on the inappropriate use of cherished cultural symbols. Personality and Social Psychology Bulletin, 21, 12211228.

Greenberg, J., Solomon, S., \& Pyszczynski, T. (1997). Terror management theory of self-esteem and social behavior: Empirical assessments and 
conceptual refinements. In M. P. Zanna (Ed.), Advances in experimental social psychology, (Vol. 29, pp. 61-139). New York: Academic Press. Greenberg, J., Solomon, S., Pyszczynski, T., Rosenblatt, A., Burling, J., Lyon, D., et al. (1992). Assessing the terror management analysis of self-esteem: Converging evidence of an anxiety-buffering function. Journal of Personality and Social Psychology, 63, 913-922.

Greenwald, A. G., Banaji, M. R., Rudman, L. A., Farnham, S. D., Nosek, B. A., \& Mellott, D. S. (1999). Unified theory of implicit social cognition. Unpublished manuscript, University of Washington.

Hamilton, D. L., \& Gifford, R. K. (1976). Illusory correlation in interpersonal perception: A cognitive basis of stereotypic judgements. Journal of Experimental Social Psychology, 12, 392-407.

Harmon-Jones, E., Simon, L., Greenberg, J., Pyszczynski, T., Solomon, S., \& McGregor, H. (1997). Terror management theory and self-esteem: Does self-esteem attenuate or intensify mortality salience effects? Journal of Personality and Social Psychology, 72, 24-36.

Jost, J. T. (1995). Negative illusions: Conceptual clarification and psychological evidence concerning false consciousness. Political Psychology, 16, 397-424.

Jost, J. T., \& Banaji, M. R. (1994). The role of stereotyping in systemjustification and the production of false consciousness. British Journal of Social Psychology, 33, 1-27.

Jost, J. T., \& Burgess, D. (2000). Attitudinal ambivalence and the conflict between group and system justification motives in low status groups. Personality and Social Psychology Bulletin, 26, 293-305.

Krueger, J., \& Clement, R. W. (1994). The truly false consensus effect: An ineradicable and egocentric bias in social perception. Journal of Personality and Social Psychology, 67, 596-610.

Leary, M. R., \& Downs, D. L. (1995). Interpersonal functions of the self-esteem motive: The self-esteem system as a sociometer. In M. H. Kernis (Ed.), Efficacy, agency, and self-esteem (pp. 123-144). New York: Plenum.

Leary, M. R., Tambor, E. S., Terdal, S. K., \& Downs, D. L. (1995). Self-esteem as an interpersonal monitor: The sociometer hypothesis. Journal of Personality and Social Psychology, 68, 518-530.

Lewin, K. (1941). Self-hatred among Jews. Contemporary Jewish Record, 4, 219-232.

Lifton, R. J. (1983). The broken connection: On death and the continuity of life. New York: Basic Books.

Major, B., Spencer, S., Schamder, T., Wolfe, C., \& Crocker, J. (1998). Coping with negative stereotypes about intellectual performance: The role of psychological disengagement. Personality and Social Psychology Bulletin, 24, 34-50.

Marques, J. M., \& Yzerbyt, V. Y. (1988). The black sheep effect: Judgmental extremity towards ingroup members in inter- and intra-group situations. European Journal of Social Psychology, 18, 287-292.

McGregor, H., Lieberman, J. D., Solomon, S., Greenberg, J., Arndt, J., Simon, L., \& Pyszczynski, T. (1998). Terror management and aggression: Evidence that mortality salience motivates aggression against worldview threatening others. Journal of Personality and Social Psychology, 74, 590-605.

McGuire, W. J., \& Padawer-Singer, A. (1976). Trait salience in the spontaneous self-concept. Journal of Personality and Social Psychology, 33, 743-754.

Nelson, L. J., Moore, D. L., Olivetti, J., \& Scott, T. (1997). General and personal mortality salience and nationalistic bias. Personality and Social Psychology Bulletin, 23, 884-892.

Ochsmann, R., \& Mathay, M. (1996). Depreciating of and distancing from foreigners: Effects of mortality salience. Unpublished manuscript, Universitat Mainz, Mainz, Germany.

Pyszczynski, T., Greenberg, J., \& Goldenberg, J. (in press). Freedom in the balance: On the defense, growth, and expansion of the self. In J. P. Tangney \& M. R. Leary (Eds.), Handbook of self and identify.
Pyszczynski, T., Greenberg, J., Solomon, S., Cather, C., Sideris, J., \& Stubing M. J. (1993). Emotional expression and the reduction of motivated cognitive bias: Evidence from cognitive dissonance and distancing from victim's paradigms. Journal of Personality and Social Psychology, 64, 177-186.

Pyszczynski, T., Wicklund, R. A., Floresky, S., Gauch, G., Koch, S., Solomon, S., \& Greenberg, J. (1996). Whistling in the dark: Exaggerated estimates of social consensus in response to incidental reminders of mortality. Psychological Science, 7, 332-336.

Rosenberg, M. (1981). The self-concept: Social product and social force. In M. Rosenberg \& R. H. Turner (Eds.), Social psychology: Sociological perspectives (pp. 591-624). New York: Basic Books.

Rosenblatt, A., Greenberg, J., Solomon, S., Pyszczynski, T., \& Lyon, D. (1989). Evidence for terror management theory: I. The effects of mortality salience on reactions to those who violate or uphold cultural values. Journal of Personality and Social Psychology, 57, 681-690.

Rosenthal, R., Rosnow, R. L., \& Rubin, D. B. (2000). Contrasts and effects size in behavioral research: A correlational approach. Cambridge, England: Cambridge University Press.

Schimel, J. A., Pyszczynski, T., Greenberg, J., O’Mahen, H., \& Arndt, J. (2000). Running from the shadow: Psychological distancing from others to deny characteristics people fear in themselves. Journal of Personality and Social Psychology, 78, 446-462.

Schimel, J., Simon, L., Greenberg, J., Pyszczynski, T., Solomon, S., Waxmonski, J., \& Arndt, J. (1999). Support for a functional perspective on stereotypes: Evidence that mortality salience enhances stereotypic thinking and preferences. Journal of Personality and Social Psychology, 77, 905-926.

Simon, L., Greenberg, J., Arndt, J., Pyszczynski, T., Clement, R., \& Solomon, S. (1997). Perceived consensus, uniqueness, and terror management: Compensatory responses to threats to inclusion and distinctiveness following mortality salience. Personality and Social Psychology Bulletin, 23, 1055-1065.

Snyder, C. R., Lassegard, M., \& Ford, C. E. (1986). Distancing after group success and failure: Basking in reflected glory and cutting off reflected failure. Journal of Personality and Social Psychology, 51, 382-388.

Solomon, S., Greenberg, J., \& Pyszczynski, T. (1991). A terror management theory of social behavior: The psychological functions of selfesteem and cultural worldviews. In M. P. Zanna (Ed.), Advances in experimental social psychology (Vol. 24, pp. 91-159). New York: Academic Press.

Spears, R., Doosje, B., \& Ellemers, N. (1997). Self-stereotyping in the face of threats to group status and distinctiveness: The role of group identification. Personality and Social Psychology Bulletin, 23, 538-553.

Spencer, S. J., Steele, C. M., \& Quinn, D. M. (1999). Stereotype threat and women's math performance. Journal of Experimental Social Psychology, 35, 4-28.

Steele, C. M. (1997). A threat in the air: How stereotypes shape intellectual identity and performance. American Psychologist, 52, 613-629.

Steele, C. M., \& Aronson, J. (1995). Stereotype threat and the intellectual performance of African Americans. Journal of Personality and Social Psychology, 69, 797-811.

Steele, S. (1990). The content of our character: A new vision of race in America. New York: St. Martin's Press.

Stone, J., Lynch, C. I., Sjomeling, M., \& Darley, J. M. (1999). Stereotype threat effects on Black and White athletic performance. Journal of Personality and Social Psychology, 77, 1213-1227.

Swan, S., \& Wyer, R. S. (1997). Gender stereotypes and social identity: How being in the minority affects judgements of self and others. Personality and Social Psychology Bulletin, 23, 1265-1276.

Tajfel, H., \& Turner, J. C. (1986). The social identity of intergroup behavior. In S. Worchel \& W. Austin (Eds.), Psychology of intergroup relations (pp. 7-24). Chicago: Nelson-Hall. 
Taubman Ben-Ari, O., Florian, V., \& Mikulincer, M. (1999). The impact of mortality salience on reckless driving: A test of terror management mechanisms. Journal of Personality and Social Psychology, 76, 35-45.

Tesser, A. (1988). Self-esteem maintenance in family dynamics. In L. Berkowitz (Ed.), Advances in experimental social psychology (Vol. 21, pp. 181-227). San Diego, CA: Academic Press.

Wann, D. L., \& Branscomb, N. R. (1990). Die-hard and fair-weather fans: Effects of identification on BIRGing and CORFing tendencies. Journal of Sport and Social Issues, 14, 103-117.

Watson, D., \& Clark, L. A. (1992). Affects separable and inseparable: On the hierarchical arrangement of the negative affects. Journal of Personality and Social Psychology, 62, 489-505.

Wylie, R. (1979). The self-concept (Vol. 2). Lincoln: University of Nebraska Press.
Received October 7, 2000

Revision received December 11, 2001

Accepted December 17, 2001 